\title{
REFORÇO DE PILARES PAREDE POR SUBSTITUIÇÃO DE CONCRETO
}

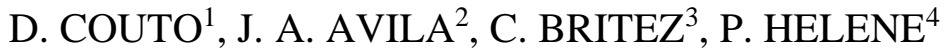 \\ ${ }^{1}$ Departamento de Estruturas (DES), Faculdade de Engenharia Civil, \\ Universidade Estadual de Campinas (Unicamp) e PhD Engenharia, São Paulo-SP, Brasil. \\ ${ }^{2}$ Avila Engenharia, Marília-SP, Brasil. \\ ${ }^{3}$ Departamento de Estruturas e Fundações (PEF), Escola Politécnica, \\ Universidade de São Paulo (USP) e PhD Engenharia, São Paulo-SP, Brasil. \\ ${ }^{4}$ Departamento de Engenharia de Construção Civil (PCC), Escola Politécnica, \\ Universidade de São Paulo (USP) e PhD Engenharia, São Paulo-SP, Brasil.
}

\section{RESUMO}

Recentemente, tem se observado a crescente demanda por projetos de reforço e recuperação estrutural em pilares de concreto armado, quer seja por mudança de uso em reformas ou retrofits de estruturas antigas ou, ainda, em estruturas novas (durante a construção); por motivos diversos relacionados com qualidade do material, erros de projeto ou falhas de execução. A maior problemática envolvida nessa solução é, na maioria dos casos, os impactos arquitetônicos causados pelo aumento da seção do elemento estrutural reforçado. Este artigo apresenta uma nova alternativa, através de um procedimento que visa manter a seção transversal original do pilar objeto de reforço, sem interferir nos aspectos estéticos e concepção arquitetônica de projeto. É apresentado um exemplo de cálculo de reforço de um pilar parede, com verificação de efeitos locais e localizados, demonstrando a viabilidade técnica dessa metodologia inovadora.

Palavras clave: Reforço; Pilares; Retrofit; Concreto Armado.

\begin{abstract}
Nowadays is observed a growing demand for structural strengthening and rehabilitation projects for reinforced concrete columns, sometimes by change of use in reforms or retrofit of old structures or, in new structures (under construction); due many reasons related to material quality, design mistakes or construction malpractice. The biggest problem in this solution is, in most of cases, the architectural impact due by increasing cross section of the strengthened structural element. This paper presents a new alternative method for structural strengthening for reinforced concrete columns, which aims to keep its original cross section, without interfere on the architectural concepts of the project. We present an example of a shear wall strengthening, and the assessment of the stability and buckling in boundary elements, showing the technical viability of this new method.
\end{abstract}

Keywords: Strengthening; Columns; Retrofit; Reinforced Concrete. 


\section{INTRODUÇÃO}

Observa-se há algum tempo a crescente demanda por projetos de reforço e recuperação estrutural, sejam motivados por reformas e retrofits em estruturas antigas, ou ainda em estruturas novas (em construção), onde a necessidade parte desde a baixa qualidade dos materiais até erros de projeto e falhas de execução. Conforme definição da ABNT NBR 6118:2014, os pilares são elementos lineares de eixo reto, usualmente verticais, onde são preponderantes os esforços de compressão, mas não podem ser desprezados os esforços horizontais e momentos. São responsáveis pela transmissão das cargas da estrutura às fundações e são agentes importantes da estabilidade global de um edifício, portanto, a sua falha ou desempenho insuficiente pode gerar graves consequências à estrutura podendo inclusive causar o colapso de uma edificação.

Em geral, o reforço de pilares de concreto envolve metodologias de cálculo e execução que visam o aumento da seção transversal de modo a prover equilíbrio aos esforços solicitantes, entretanto, na maioria dos casos, aumentos de seção podem gerar impactos negativos importantes na arquitetura e na funcionalidade da estrutura, como a redução de espaço entre vagas de garagem e alterações na fachada, por exemplo. (HELENE \& HARTMANN, 2003)

Em casos assim é comum se realizar a substituição total do concreto, com ou sem acréscimo de armaduras, de modo a não se alterar a seção transversal prevista em projeto, entretanto, essa metodologia pode exigir o escoramento total da estrutura para viabilizar sua execução. Outras metodologias ainda envolvem o encamisamento da seção com concreto e armaduras ou ainda perfis e chapas metálicas, porém são soluções que alteram a geometria inicial do elemento, podendo interferir na arquitetura e no uso da estrutura. (CÁNOVAS, 1988; TAKEUTI, 2003; HELENE, 2003)

Este artigo tem como objetivo realizar uma breve revisão sobre alguns procedimentos de reforços de pilares de concreto, bem como propor um novo procedimento com uso de concreto de alta resistência para o reforço de pilares, dispensando escoramentos custosos e mantendo as dimensões originais, eliminando assim eventuais impactos com os demais sistemas construtivos e, principalmente, com a arquitetura da edificação.

\section{REFORÇO DE PILARES EM ESTRUTURAS DE CONCRETO ARMADO}

Como já citado, os pilares tem papel fundamental em uma estrutura, sendo agentes de estabilidade e responsáveis pela transmissão dos esforços às fundações. Pode-se dizer, com base nisso, que os pilares são (juntamente com as fundações), os principais elementos da estrutura de uma edificação.

Dada sua importância deve-se tratar o reforço de pilares de forma a conferir um comportamento adequado ao elemento estrutural frente às solicitações a que está submetido, e ao mesmo tempo respeitar os limites de deformação e os critérios de ductilidade estabelecidos nos mais diversos códigos e normas de projeto.

Apesar do tema Terapia das Estruturas ser ainda carente de normalização técnica e procedimentos claros de análise, já existem pesquisas sobre diversas técnicas de reforço, com uso de modelos físicos e numéricos, que possuem boa correlação e são amplamente empregados no reforço e recuperação de estruturas de concreto. (CANOVAS, 1988; TAKEUTI, 2003)

Assim, além da garantia de estabilidade, o reforço deve levar em conta os aspectos ligados à durabilidade, sendo necessário, precedentemente ao projeto de intervenção corretiva, a análise da classe de agressividade ambiental a que essa estrutura está exposta, de modo a se prever a eventual necessidade de proteções superficiais adicionais.

\subsection{Métodos de reforço}

Apesar de não haver ainda normatização específica para metodologias de reforço de estruturas, é conveniente que sejam aplicadas nessas situações a maioria dos critérios estabelecidos para o 
dimensionamento de estruturas novas. Entretanto, em determinados casos, há de se fazer uma análise mais detalhada das estruturas de concreto, com objetivo de se atingir uma situação de dimensionamento que confira ao elemento as propriedades resistentes necessárias, e que atenda a critérios mínimos de ductilidade e segurança em seus estados limites.

Variáveis como deformabilidade, características mecânica dos materiais, aderência, etc. devem ser conhecidas preliminarmente, para que se possa avaliar a melhor metodologia para o projeto e execução do reforço. Além disso, restrições de arquitetura, como vagas de garagem, por exemplo, podem ser um fator determinante na viabilidade de um dado tipo de solução. (VALLE, 1983; CÁNOVAS, 1988; TAKEUTI, 2003)

\subsubsection{Reforço com aumento de seção ou encamisamento com material concreto}

O conceito básico do reforço por encamisamento consiste em criar uma área adicional, ou aumento de seção, com objetivo de diminuir a tensão solicitante no trecho reforçado. Esse método também, quando empregado em todo o contorno do elemento, aumenta as condições de confinamento da seção original. A Fig. 2.1 mostra as configurações típicas de reforço por aumento de seção. (TAKEUTI,1999; HELENE, 2003; JULIO et al., 2005; CAMPIONE et al., 2014)


Figura 2.1 - Configurações típicas de reforço de pilar por aumento de seção.

(TAKEUTI, 2003)

Um dos fatores para a definição da espessura da "camisa", além da carga, é o espaço necessário para alojamento das armaduras. Conforme as recomendações de Cánovas (1988), não se deve utilizar espessuras de capa menores que $10 \mathrm{~cm}$. Entretanto, atualmente, com a possibilidade da utilização de microconcretos e grautes industrializados de alta resistência e elevada fluidez, consegue-se trabalhar com espessuras da ordem de $6 \mathrm{~cm}$ a $7 \mathrm{~cm}$, dependo do diâmetro da armadura longitudinal. (HELENE, 2003; TAKEUTI, 2003)

Em casos onde há necessidade de espessuras maiores, como alternativa pode se remover parte do cobrimento do pilar original a ser reforçado, conferindo assim um espaço adicional com menor aumento da seção transversal (do elemento final reforçado). Porém ainda haverá o fato do impacto arquitetônico da solução, principalmente em vagas de garagem, caixas de escada/elevadores e fachadas, onde essa solução pode ser inviável do ponto de vista estético e funcional. (CÁNOVAS, 1983; TAKEUTI, 2003) Nos casos de encamisamento onde se considera o cintamento (ou confinamento) da seção transversal, há um considerável aumento da ductilidade da seção, devendo-se prever detalhadamente no dimensionamento uma armadura transversal compatível com esse tipo de comportamento. Em geral, se tem um comportamento perfeitamente cintado no caso de pilares cilíndricos (Fig. 2.2), com armadura transversal na forma de espiral com espaçamento apropriado, capaz de conter as deformações transversais do elemento quando este está sujeito a esforços longitudinais (razão de Poisson) (HELENE, 2003; TAKEUTI, 2003; WIGHT \& MacGREGOR, 2011)

Valle (1983) e Cánovas (1988) recomendam ainda que, para que possa considerar um pilar como cintado, o espaçamento " $t$ " entre as espiras seja, conforme (2.1): 


$$
t \leq\left\{\begin{array}{l}
1 / 5 \cdot a \\
8 \cdot \phi \\
8 c m
\end{array}\right.
$$

Onde:

a $\rightarrow$ diâmetro da seção original (núcleo);

$\Phi \rightarrow$ diâmetro da armadura longitudinal.



Figura 2.2 Cintamento com uso de pilar cilíndrico. (CÁNOVAS, 1988)

Ainda por este método, conforme Takeuti (1999), a capacidade resistente do pilar cintado deve ser limitada pela expressão (2.2) e o dimensionamento da armadura de cintamento deve ser verificado via método da ruptura, conforme expressão 2.3.

$$
\begin{aligned}
& \gamma_{f} \cdot N=26 \cdot a^{2} \cdot \frac{f_{c k}}{\gamma_{c}} \\
& A_{t}=\frac{\gamma_{f} \cdot N-0,7 \cdot B_{i} \cdot f_{c d}-A_{s} \cdot f_{y d}}{1,15 \cdot f_{y d}}
\end{aligned}
$$

$\gamma_{f} \rightarrow$ coeficiente parcial de majoração das ações;

$\gamma_{c} \rightarrow$ coeficiente parcial de minoração das resistências;

$f_{c k} \rightarrow$ resistência à compressão, valor característico, do concreto do núcleo.

$B_{i} \rightarrow$ área do núcleo;

$f_{c d} \rightarrow$ resistência à compressão, valor de cálculo, do concreto do núcleo;

$f_{y k} \rightarrow$ resistência à tração do aço.

Ressalta-se que as referências bibliográficas mencionadas recomendam também a consideração do cintamento apenas para pilares curtos. No caso de pilares esbeltos há que se levar em conta outros procedimentos, como também deve ser verificado os limites de deformação de cada elemento e eventuais acréscimos de carga em vigas e lajes.

Há também a possibilidade de reforço de pilares através do uso de elementos metálicos e compósitos como fibras de carbono. Ambos os métodos visam conferir comportamento similar ao reforço por concreto armado, porém devem ser observadas as particularidades de dimensionamento de cada procedimento, bem como suas limitações, como resistência ao fogo, por exemplo, no caso de incêndios. (CHOI et al., 2010; PÁDUA et al., 2012; CAMPIONE et al., 2014) 


\subsubsection{Reforço por substituição total do concreto da seção}

Diferentemente dos métodos de encamisamento acima mencionadas, em casos de não conformidade do concreto é comum a recomendação, por parte dos projetistas estruturais, de se proceder com a substituição do concreto nos elementos onde a resistência não atingiu o patamar mínimo de segurança. Nesse tipo de recuperação, é necessário prover um sistema adequado de escoramento da estrutura, demolir o pilar por etapas (Fig. 2.3), ou totalmente (Fig. 2.4), e executar o preenchimento de cada trecho, ou de todo o pilar (em caso de demolição em etapa única), com concreto de resistência compatível com a especificada em projeto, até que $100 \%$ do pilar esteja com concreto considerado adequado. (HELENE, 2003)

Entretanto, com a disponibilidade, nos dias de hoje, de materiais de alto desempenho, é possível obter em canteiro de obras resistências de até $100 \mathrm{MPa}$, com uso de grautes e microconcretos industrializados. Sendo essa uma grande vantagem a ser explorada no desenvolvimento de projetos de reforço e recuperação estrutural.


Figura 2.3 Exemplo de sistema de reforço por substituição total do concreto com demolição do pilar por etapas. (Acervo do autor)
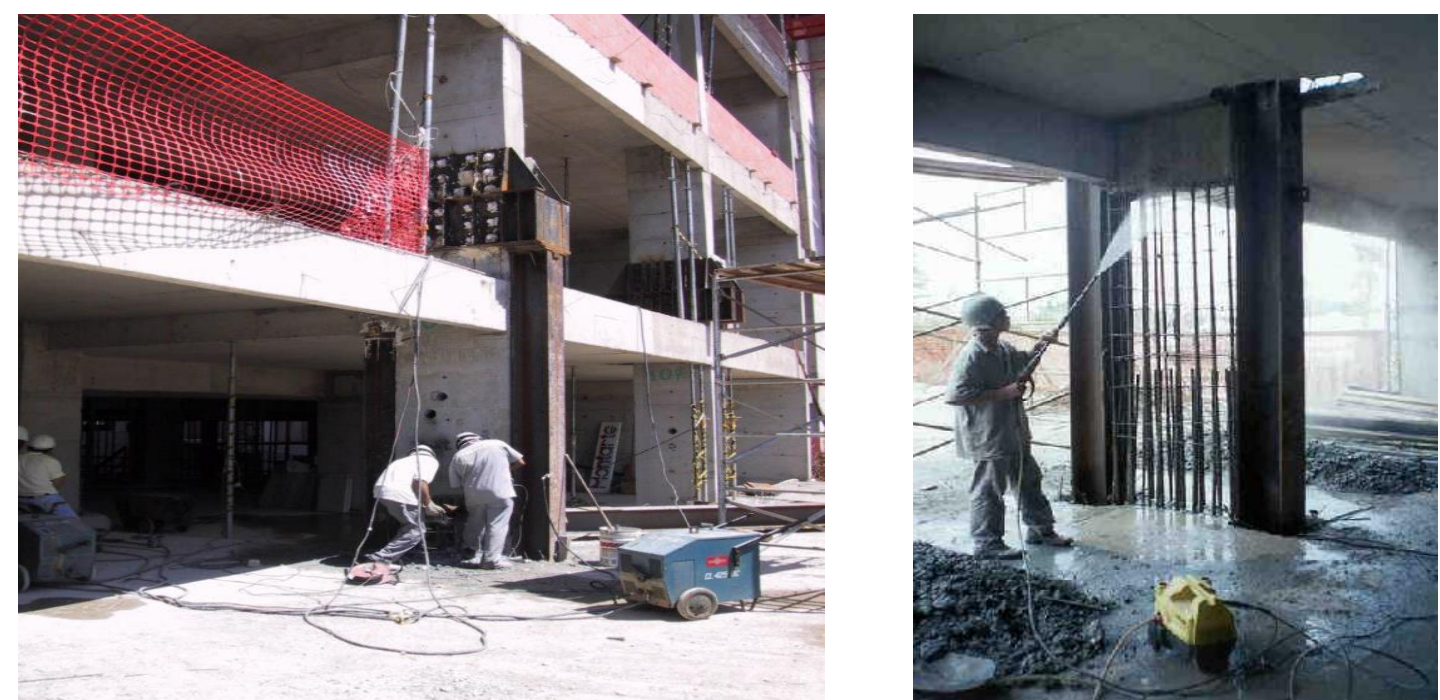

Figura 2.4 Exemplo de sistema de escoramento e demolição de $100 \%$ de pilar para substituição de concreto não-conforme. (HELENE, 2003) 


\section{METODOLOGIA PROPOSTA}

Tomando por base a técnica de reforço por substituição do concreto, do item precedente, é possível realizar a verificação estrutural de pilares com partes de sua seção transversal com diferentes módulos e resistências, de modo que não seja necessário substituir $100 \%$ do concreto de uma seção para que se tenha a envoltória resistente do pilar reestabelecida.

\subsection{Exemplo da metodologia proposta}

Considera-se um exemplo numérico de um pilar parede hipotético, com problema de concreto não conforme e com necessidade de reforço, sendo a seção transversal $19 \mathrm{~cm}$ x $224 \mathrm{~cm}$ (Fig. 3.2). O pilar possui $\boldsymbol{f}_{\boldsymbol{c} \text { c }}$ de projeto de $35 \mathrm{MPa}$ e, assume-se a hipótese de resistência de testemunhos extraídos $\left(\boldsymbol{f}_{\boldsymbol{c k} \text {,ext }}\right)$, igual a $25 \mathrm{MPa}$ (ou seja, 30\% menor que o especificado), mesmo depois de corrigidos conforme a ABNT NBR 7680-1:2015.

Supondo um pilar em ambiente interno, revestido e com umidade controlada, o cobrimento nominal adotado é de 2,5 cm, correspondente à classe de agressividade ambiental I da ABNT NBR 6118:2014. Conforme os itens 14.4.2.4 e 15.9.1 da ABNT NBR 6118:2014, o elemento em questão trata-se de um pilar parede, e deve ter os efeitos locais e localizados de $2^{\mathrm{a}}$ ordem avaliados adequadamente.

Partindo da premissa que o projeto original desse elemento, com $f_{c k}=35 \mathrm{MPa}$, foi elaborado em conformidade com a norma ABNT NBR 6118:2014, procede-se com as verificações com base na resistência obtida in situ, e então se avalia a necessidade e configuração do reforço a ser empregado, conforme metodologia expressa por COUTO et al. 2015.


Dados do dimensionamento:

$N_{d}: 7876 \mathrm{kN}$;

$M_{d, x, t o p o}: 95,0 \mathrm{kN} \cdot \mathrm{m}$;

$M_{d, x, \text { base }}: 2,0 \mathrm{kN} \cdot \mathrm{m}$;

$M_{d, y, t o p o}: 1159,6 \mathrm{kN} \cdot \mathrm{m}$;

$M_{d, y, \text { base: }}: 1050,5 \mathrm{kN} \cdot \mathrm{m}$;

$f_{c k}=35 \mathrm{MPa}$;

$f_{\text {ck,ext: }} 25 \mathrm{MPa}$;

armadura longitudinal efetiva: $30 \Phi 25 \mathrm{~mm}$;

cobrimento nominal: $2,5 \mathrm{~cm}$.

Figura 3.2. Pilar parede hipotético para exemplo de reforço.

Inicialmente, com uso do módulo de verificação de pilares de software TQS v.18, realiza-se a verificação dos efeitos locais do elemento, onde se concluí que, embora os esforços solicitantes estejam ainda cobertos pela envoltória resistente do pilar, a envoltória mínima de segunda ordem não é atendida, conforme ilustram as Figs. 3.3 e 3.4 


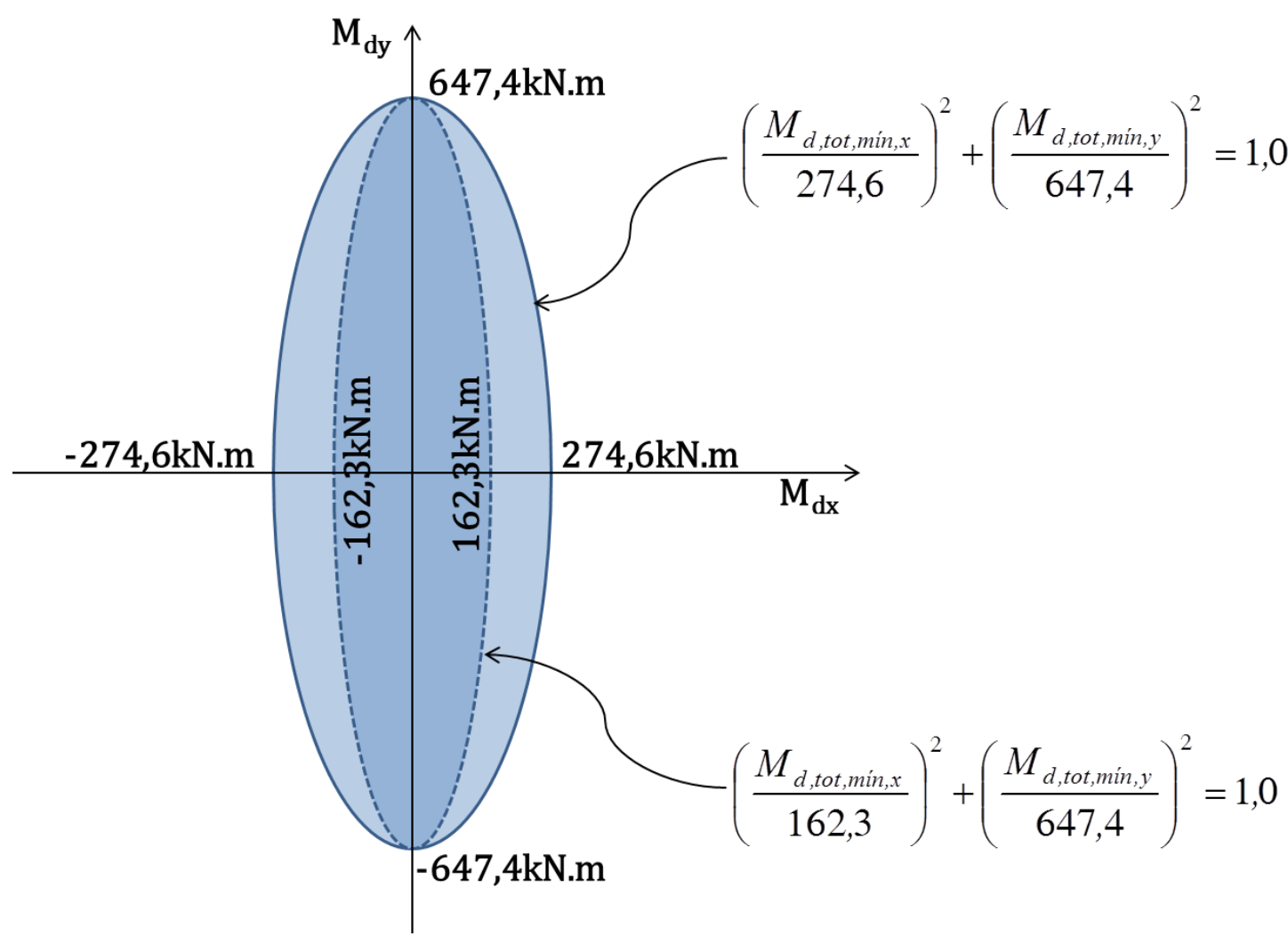

Figura 3.3. Envoltória mínima de primeira e segunda ordem obtida para o pilar parede.

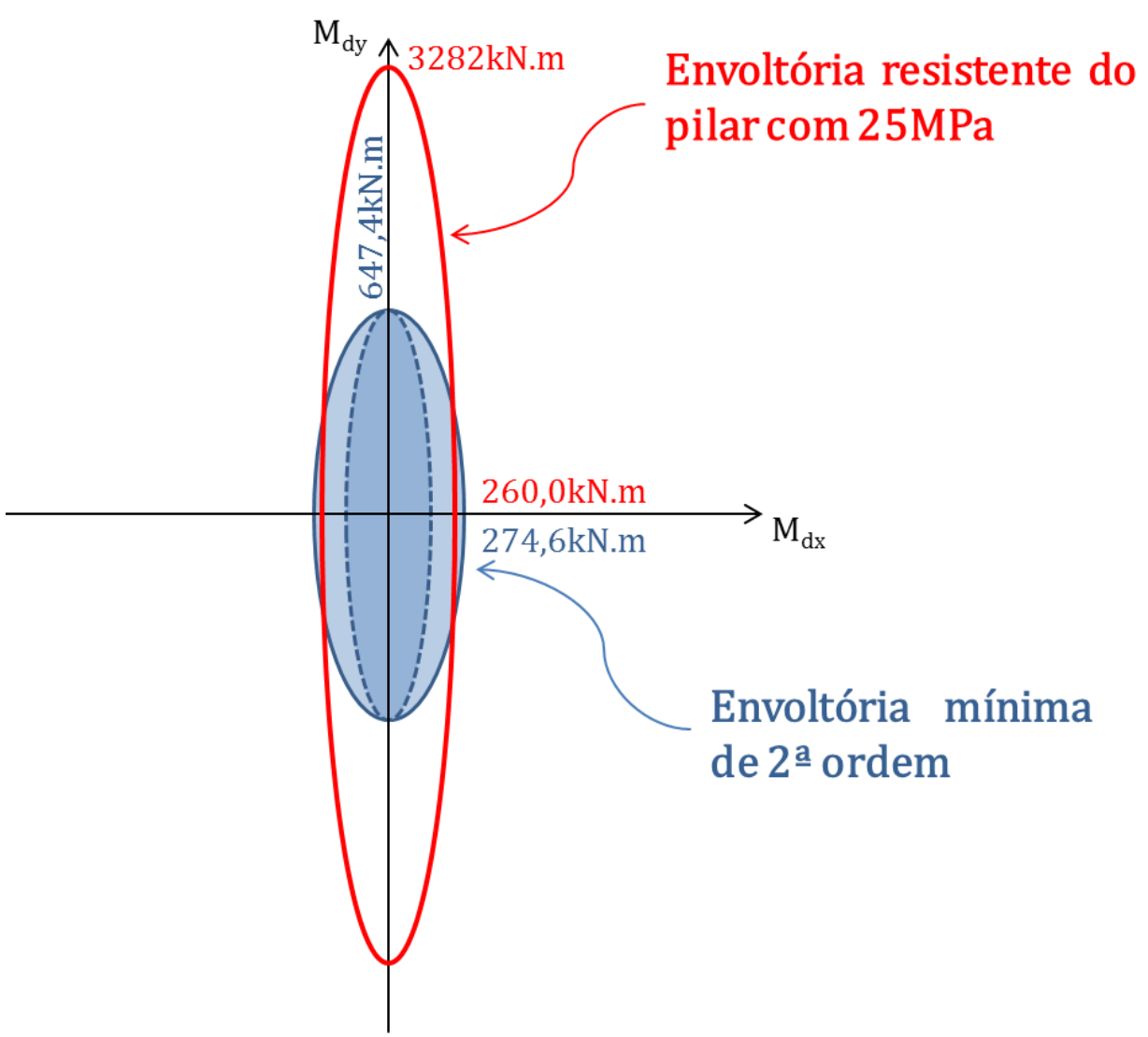

Figura 3.4. Comparação da envoltória resistente do pilar e envoltória de momentos mínimos de $1^{\mathrm{a}}$ e $2^{\mathrm{a}}$ ordem. 
Assim, a primeira intervenção a se realizar nesse pilar, seria o complemento da resistência do concreto, com vistas a cobertura da envoltória mínima de segunda ordem, seguida da verificação dos efeitos localizados nas lâminas do pilar parede, conforme a seção 15 da ABNT NBR 6118:2014.

Em um raciocínio simplificado, avaliando em um primeiro momento apenas a resistência de concepção (35MPa), a envoltória resistente desse pilar seria reestabelecida adotando-se uma resistência do concreto de 70MPa (dobro da resistência original), distribuída simetricamente na metade da área do pilar. Equivalente a substituição do concreto das pontas do pilar conforme ilustra a Fig. 3.4.



Figura 3.4. Configuração hipotética de substituição parcial do concreto para reestabelecimento da capacidade do pilar à carga vertical.

Entretanto, ao se realizar a verificação localizada nas lâminas do pilar parede, essa configuração dada pelo esquema da Fig. 3.4 se mostra insuficiente, uma vez que as lâminas intermediárias não tem comportamento resistente adequado aos efeitos localizados de $2^{\mathrm{a}}$ ordem, como mostra o diagrama da Fig. 3.5.



Pilar parede dividido em 4 lâminas.

Esforços solicitantes por faixa:

Faixas 1 e 4

$\mathrm{N}_{\mathrm{d} \text {,faixa }}=2518 \mathrm{kN}$

$\mathrm{M}_{\mathrm{dx}, \text { faixa }}=24 \mathrm{kN} \cdot \mathrm{m}$

Faixas 2 e 3

$\mathrm{N}_{\mathrm{d} \text {,faixa }}=2148 \mathrm{kN}$

$\mathrm{M}_{\mathrm{dx}, \text { faixa }}=24 \mathrm{kN} \cdot \mathrm{m}$

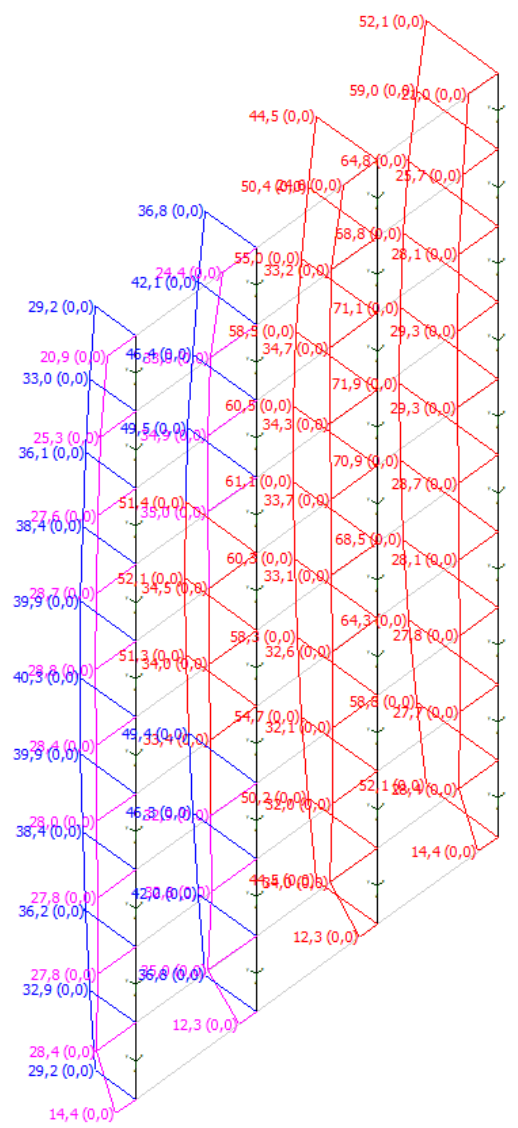

Envoltória de esforços

Figura 3.5. Verificação das lâminas do pilar parede com $f_{c k} 25 \mathrm{MPa}$. 
Nota-se pela Fig. 3.5, que a lâmina 3 do pilar (e lâmina 2 no caso de inversão de momento), não atendem a verificação de efeitos localizados de $2^{\mathrm{a}}$ ordem $\operatorname{com} f_{c k}$ de $25 \mathrm{MPa}$, ou seja, apenas o reestabelecimento da capacidade do pilar à carga vertical, mostra-se insuficiente para se atender aos critérios de dimensionamento da ABNT NBR 6118:2014.

Assim, deve-se proceder com uma nova configuração geométrica da parte reforçada (substituída), de modo que a verificação aos efeitos localizados de $2^{\mathrm{a}}$ ordem seja satisfeita em todas as regiões do pilar. Adotando agora uma configuração de lâminas com área de concreto substituída equivalente a cerca de $2 / 3$ do pilar (com $3 h \leq a_{i} \leq 100$ ), conforme Fig. 3.6, procede-se com nova verificação dos efeitos de $2^{\text {a }}$ ordem, mantendo o núcleo central com o concreto original de $25 \mathrm{MPa}$.

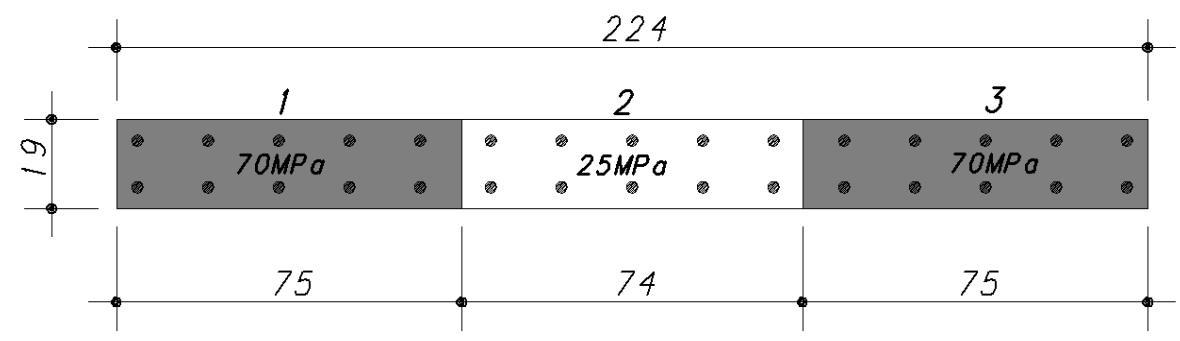

Esforços solicitantes por faixa:

Faixa 1 e 3

$\mathrm{N}_{\mathrm{d} \text {,faixa }}=3289 \mathrm{kN}$

$\mathrm{M}_{\mathrm{dx}, \text { faixa }}=31,8 \mathrm{kN} \cdot \mathrm{m}$
Faixa 2

$\mathrm{N}_{\mathrm{d} \text {,faixa }}=2595 \mathrm{kN}$

$\mathrm{M}_{\mathrm{dx}, \text { faixa }}=31,4 \mathrm{kN} \cdot \mathrm{m}$

Figura 3.6 - Configuração de substituição do concreto no pilar com cerca de 2/3 da área substituída e manutenção do núcleo central (com 1/3).

Neste caso nota-se, conforme os diagramas da Figs. 3.7, que a lâmina central (2) verificada com $f_{c k}$ de $25 \mathrm{MPa}$, se mostra adequada a verificação dos efeitos localizados, assim como as lâminas de extremidade possuem envoltórias adequadas aos esforços solicitantes e aos momentos mínimos de $1^{\mathrm{a}} \mathrm{e}$ $2^{\mathrm{a}}$ ordens.

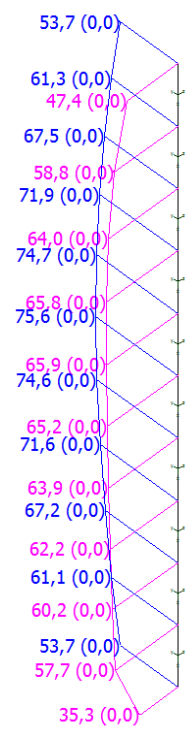

(a) - Lâmina Central - 2 (25 MPa)

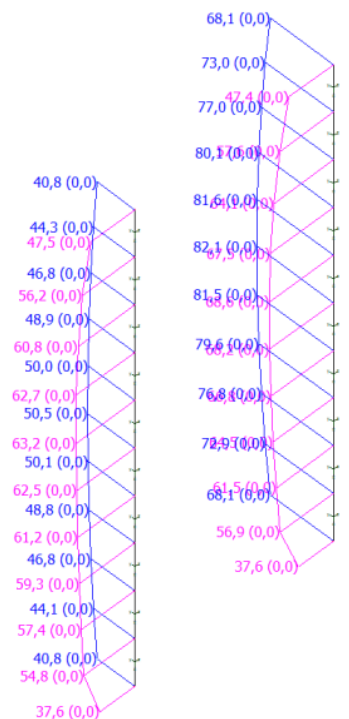

(b) - Lâminas de extremidade - 1 e 3 (70 $\mathrm{MPa})$

Figura 3.7 - (a) Verificação da lâmina central com $f_{c k} 25 \mathrm{MPa}$; (b) Verificação das lâminas de extremidade $\operatorname{com} f_{c k} 70 \mathrm{MPa}$. 
Nessa nova configuração, com duas extremidades tendo $f_{c \mathrm{k}} 70 \mathrm{MPa}$ e núcleo com $\boldsymbol{f}_{\boldsymbol{c} \text { k }} 25 \mathrm{MPa}$, são satisfeitas todas as verificações da ABNT NBR 6118:2014 para pilares parede, inclusive a nova envoltória de momentos mínimos, conforme mostrado na Fig. 3.8.

\section{Momentos mínimos faixas 1 e 3 $70 \mathrm{MPa}$}
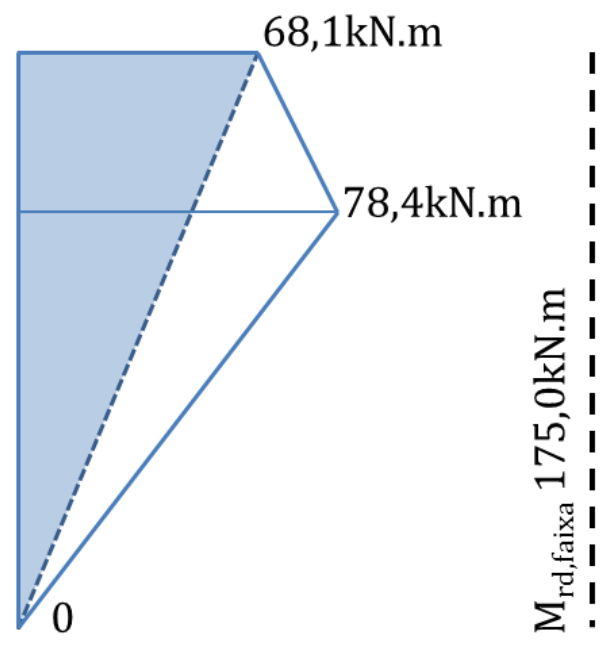

\section{Momentos mínimos faixa 2 $25 \mathrm{MPa}$}

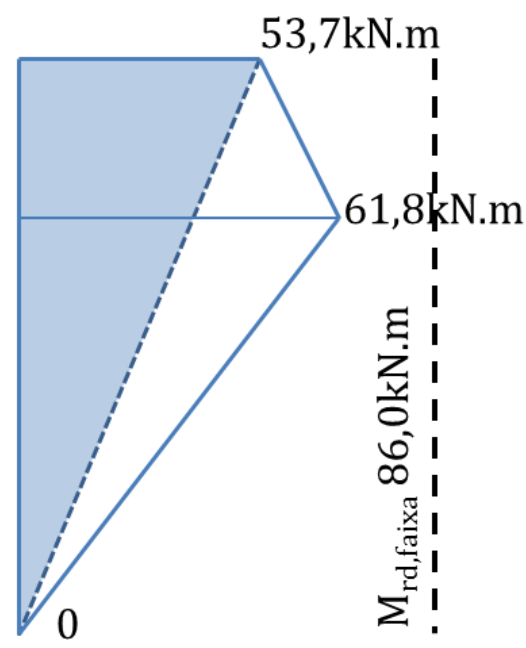

Figura 3.8 Envoltória de momentos mínimos das faixas após o reforço.

\subsection{Procedimento executivo empregado neste reforço.}

Todo procedimento de execução de reforço estrutural deve ser cuidadosamente estudado precedente ao seu início, pois em certos casos, durante a execução do reforço, a estrutura pode passar por situações críticas, com nível de segurança abaixo dos limites normativos, principalmente em reforços que requerem a demolição parcial de determinados elementos estruturais.

Como o procedimento proposto neste artigo consiste na demolição e reconstrução de trechos verticais do pilar, é necessário avaliar o impacto da demolição de parte do elemento em função da carga atuante no pilar no momento do reforço.

Em geral, para se evitar o uso de sistemas de escoramento em vários pavimentos, sugere-se que a demolição de cada trecho do pilar seja feita por etapas, e o dimensionamento dos trechos a serem demolidos em cada etapa, deve respeitar o limite da capacidade resistente do restante da seção transversal, ou seja, a parte não demolida do pilar atua como elemento resistente durante o processo de execução do reforço, e deve ser capaz de resistir à carga vertical atuante.

Observa-se que na fase de demolição de cada trecho, devem ser escoradas vigas e lajes no entorno do pilar, de modo que a demolição de trechos de ancoragem não causem impactos negativos no restante da estrutura. Outro ponto importante a se considerar é que cada trecho do reforço deve ser executado isoladamente, o que significa não demolir mais de um trecho até o que anterior tenha resistência adequada para contribuir na sustentação da carga atuante no pilar.

Assim, esse procedimento mostra-se muito eficiente e eficaz em casos de estruturas ainda em construção, que necessitem de reforço devido a não conformidade do concreto, sendo mais eficiente quanto mais cedo for identificado o problema e iniciada a intervenção.

Já em casos de estruturas acabadas, com a edificação trabalhando a plena carga, devem ser estudados sistemas temporários de transição de carga, caso a demolição parcial resulte numa seção transversal insuficiente.

Resumidamente, definido em projeto a geometria dos trechos a serem demolidos e reconstruídos, bem como as etapas de demolição, a sequência executiva do reforço citado no exemplo deste artigo seria: 
- Escoramento no andar localizado e demarcação dos trechos a serem demolidos;

- Demolição do primeiro trecho (Etapa 1);

- Montagem das formas providas de cachimbo;

- Concretagem do primeiro trecho com material indicado em projeto.

- Repetição do mesmo ciclo para a Etapa 2.

Após o trecho executado na primeira etapa apresentar resistência adequada, inicia-se o mesmo procedimento para o próximo trecho, e assim sucessivamente até o término do reforço. Esse ciclo de execução pode ser observado na Fig. 3.9, de forma ilustrativa.
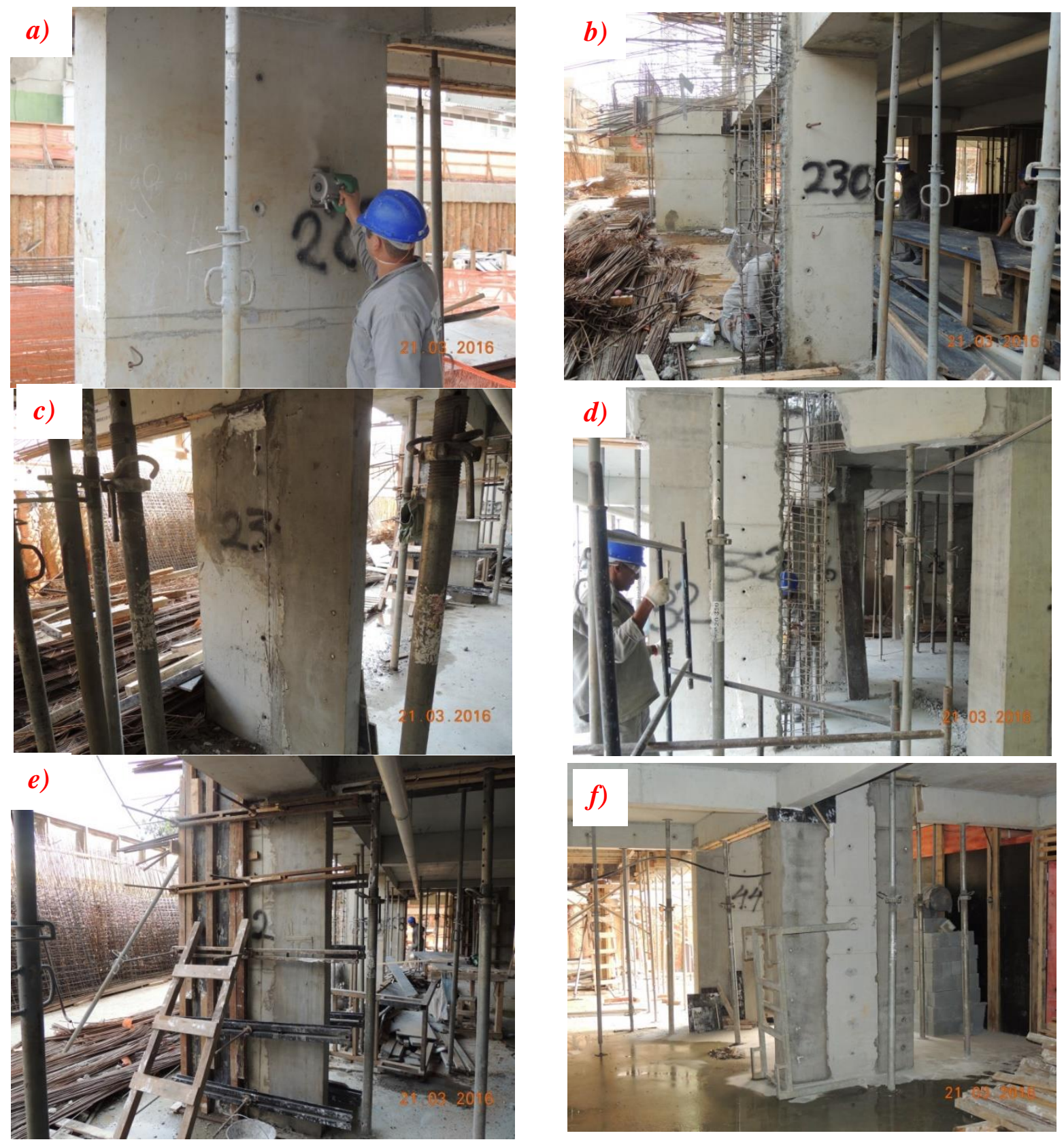

Figura 3.9 - a) Demarcação e escoramento localizado do pilar; b) Demolição do primeiro trecho do reforço; c) Primeiro trecho do reforço executado; d) Demolição do segundo trecho do reforço; e)

Concretagem do segundo trecho do reforço; f) Pilar finalizado com extremidades reforçadas e núcleo mantido. 


\section{DISCUSSÃO}

O reforço de pilares através da metodologia proposta neste artigo tem se mostrado uma alternativa viável em casos em que as restrições arquitetônicas impedem alterações geométricas da estrutura e já foi aplicado em algumas obras espalhadas pelo território nacional.

Além de não ser necessário aumento nas dimensões do pilar, nota-se que essa técnica de reforço possibilita uma execução veloz, devido ao rápido ganho de resistência do material empregado. Além disso, através da manutenção do núcleo, obtém-se valores de deformação axial nos pilares menores do que quando da remoção total do concreto.

Há também outro fator importante que é a eliminação da necessidade de sistemas de escoramento robustos, sendo necessário escorar apenas os limítrofes da intervenção, uma vez que o pilar é demolido e reconstruído por etapas.

Um ponto importante a se observar no reforço de pilares paredes com uso dessa técnica, diz respeito à concepção estrutural do edifício, pois conforme observam França \& Kimura (2006), em certas configurações estruturais, tais pilares podem estar submetidos a torção, o que deve ser levado em conta no dimensionamento do reforço. Dessa forma, recomenda-se sempre avaliar os esforços através do modelo estrutural como um todo (análise global).

Em obras em execução, um fator limitante para a execução das demolições parciais é o nível de carga a que o pilar está submetido, sendo necessário verificar os estágios de demolição e esforços atuantes na seção parcialmente demolida, prevendo sistemas de escoramento caso necessário.

\section{CONCLUSÕES}

Conforme o exposto neste artigo, os autores consideram essa técnica de reforço viável sempre que houver restrições arquitetônicas que não permitam variações geométricas dos elementos estruturais, neste caso específico, dos pilares.

Em pilares retangulares, que não pilares paredes, há a possibilidade de executar o mesmo conceito de reforço, através do dimensionamento de uma coroa externa resistente, porém em pilares de pequenas dimensões, tal técnica não se demonstra adequada, sendo recomendável a substituição total do concreto em elementos com essas características.

Sobre o comportamento estrutural do novo pilar constituído por concretos de módulo e resistências diferentes, devido a maior rigidez dos extremos do elemento, e também ao comportamento de casca, admite-se que o fluxo maior de tensões tende a se dar pelas extremidades, entretanto seria necessário proceder com ensaios em modelos físicos para avaliar adequadamente esse comportamento.

Igualmente, tal qual a pesquisa desenvolvida por Takeuti et al. (2013), seria de grande contribuição uma avaliação experimental do comportamento de pilares pré-carregados e reforçados com uso desta técnica.

Sobre os aspectos executivos, considera-se que cuidados especiais devam ser tomados quando ao planejamento das demolições, bem como a área do pilar que será demolida em cada etapa de execução, visando não colocar o elemento sob risco de colapso durante a execução do reforço. Nesse aspecto é necessário executar esse tipo de trabalho com mão-de-obra devidamente treinada.

Ainda, sobre estruturas em execução, considera-se que, havendo planejamento e estudo adequados, é perfeitamente possível executar os reforços sem a necessidade de paralização da execução da obra, resguardadas as limitações de carga dos elementos sob reforço.

Por fim, tanto no uso do procedimento indicado neste artigo, quanto em outros procedimentos conhecidos de reforço estrutural, é altamente recomendável proceder com a monitoração da estrutura havendo, durante a fase de execução do reforço, interação com o projetista estrutural e a equipe de campo, de modo a evitar situações onde a segurança da estrutura seja prejudicada. 


\section{REFERENCIAS}

American Concrete Institute (2014), ACI-318 Building Code Requirements for Structural Concrete. Farmington Hills.

Associação Brasileira de Normas Técnicas (2014). NBR 6118 - Projeto de estruturas de concreto Procedimento. ABNT, Rio de Janeiro.

Associação Brasileira De Normas Técnicas (2015). NBR 7680 - Concreto - Extração, preparo, ensaio e análise de testemunhos de estruturas de concreto. Parte 1: Resistência à compressão axial. ABNT, Rio de Janeiro.

Associação Brasileira De Normas Técnicas (2014). NBR 12655 - Concreto de cimento Portland Preparo, controle, recebimento e aceitação - Procedimento. ABNT, Rio de Janeiro.

Campione, G.; Fossetti, M.; Giacchino, C.; Minafo, G. (2014). RC columns externally strengthened with RC jackets. Materials and Structures, v. 47, n. 10, p. 1715-1728, ISSN 1359-5997.

Cánovas, M. F. Patologia e terapia do concreto armado. $1^{\text {a }}$ Ed. PINI. São Paulo, 1988.

Choi, E.; Chung, Y., Park, J.; Cho, B. (2010). Behavior of Reinforced Concrete Columns Confined by New Steel-Jacketing Method. ACI Structural Journal, v. 107, n. 6, p. 654-662, Nov-Dec, 2010. ISSN 0889-3241.

Couto, D.; Carvalho, M.; Cintra, A.; Helene, P. (2015). Concrete structures. Contribution to the safety assessment of existing structures. Ibracon Structures and Materials Journal. v.8, n.3, p. 365-389. June 2015. ISSN 1983-4195.

França, R. L. S.; Kimura, A. E. (2006), Resultados de recentes pesquisas para o dimensionamento das armaduras longitudinal e transversal em pilares-parede. Palestra apresentada no $9^{\circ}$ ENECE-ABECE. Out, 2006.

Helene, P. R. L. (2003). Manual de reparo, reforço e proteção de estruturas de concreto. Red Rehabilitar. São Paulo, 718 p.

Helene, P. R. L.; Hartmann, C. T. (2003), HPCC in Brazilian office tower. Concrete International, v. 25, n. 12, p. 64-68, Dec. 2003.

Instituto Brasileiro do Concreto (2015), ABNT NBR 6118:2014 Comentários e Exemplos de Aplicação. Ibracon, São Paulo, 2015.

Júlio, E. S.; Branco, F. B.; Silva, V. D. (2005), Reinforced Concrete Jacketing-Interface Influence on Monotonic Loading Response. ACI Structural Journal. v.102, n.2, p. 252-257, Mar. 2005. ISSN: 08893241.

Wight, J. K.; MacGregor, J. G. (2011). Reinforced Concrete - Mechanics \& Desing. 6th edition. Pearson-Prentice Hall, New York, ISBN 978-0132176521.

Takeuti, A. R. (2003), Comportamento resistente imediato e ao longo do tempo de pilares reforçados por meio de encamisamento com concreto de alto desempenho. Tese (Doutorado em Engenharia de Estruturas) - Escola de Engenharia de São Carlos, (EESC-USP). São Carlos.

Takeuti, A. R.; Hanai, J. B.; Mirmiran, A. (2008), Preloaded RC columns strengthened with highstrength concrete jackets under uniaxial compression. Materials and Structures, v. 41, n. 7, p. 12511262, Aug. 2008. ISSN 1359-5997.

Valle, E. G. (1983), Estruturas de hormigón armado: refuerzo mediante hormigón y estructura metálica. In: Curso de rehabilitacion: 5. La Estructura. p.173-179. Colégio Oficial de Arquitectos de Madrid. Madrid. 